Review

\title{
Graphene and Two-Dimensional Materials for Optoelectronic Applications
}

\author{
Andreas Bablich, Satender Kataria and Max C. Lemme * \\ Department of Electrical Engineering and Computer Science, University of Siegen, Hölderlinstr. 3, 57076 Siegen, \\ Germany; andreas.bablich@uni-siegen.de (A.B.); satender.kataria@uni-siegen.de (S.K.) \\ * Correspondence: max.lemme@uni-siegen.de; Tel.: +49-271-740-4035; Fax: +49-271-740-14035 \\ Academic Editor: Frank Schwierz
}

Received: 21 January 2016; Accepted: 4 March 2016; Published: 21 March 2016

\begin{abstract}
This article reviews optoelectronic devices based on graphene and related two-dimensional (2D) materials. The review includes basic considerations of process technology, including demonstrations of 2D heterostructure growth, and comments on the scalability and manufacturability of the growth methods. We then assess the potential of graphene-based transparent conducting electrodes. A major part of the review describes photodetectors based on lateral graphene p-n junctions and Schottky diodes. Finally, the progress in vertical devices made from 2D/3D heterojunctions, as well as all-2D heterostructures is discussed.
\end{abstract}

Keywords: graphene; $\mathrm{MoS}_{2} ; \mathrm{TMD}$; photodetectors; 2D materials; heterostructure

\section{Introduction}

Two-dimensional (2D) materials are very promising with respect to their integration into optoelectronic devices. Even though the technology readiness levels are still low and device manufacturability and reproducibility remain a challenge, graphene technology can be found in research labs around the globe. The same challenges apply to other 2D materials, like silicene, germanene, stanene and phosphorene, or for transition metal dichalcogenides (TMDs) to a much greater extent. Nevertheless, the scientific community has been able to demonstrate the enormous potential of 2D materials in numerous prototype devices and systems. This article discusses the state-of-the-art of developments in optoelectronic devices based on 2D materials and their applications.

Optoelectronic devices are electronic devices that use either electric charge to generate light, like light emitting diodes and lasers, or use light to generate electric current, like photovoltaic devices and photodetectors (PDs). The field can be subdivided into different areas depending on the physical mechanisms responsible for photon or charge generation that are exploited for device operation. Photoemission, radiative recombination, stimulated emission, photoconductivity and the photoelectric effect are examples for the mechanisms that optoelectronic devices might exploit. This review focuses on devices utilizing photoconductivity and the photoelectric effect.

To maximize the amount of photons to be converted into electron/hole pairs, a high material absorbance is required. Consequently, the absorbance (A) and the transmittance (T) are the key parameters for optoelectronic materials. The integration of 2D materials into photonic devices is promising, as they tend to absorb a significant amount of photons per layer. For example, graphene has a broadband light absorption of $2.3 \%$ below $3 \mathrm{eV}$ [1] that linearly scales with the number of layers [2], despite being only one atom thick. The absorbance of graphene depends on the fine structure constant $\alpha=\frac{e^{2}}{\hbar c}$, where $\mathrm{c}$ is the speed of light, $\mathrm{e}$ is the charge of an electron and $\hbar$ is Planck's constant divided by $2 \pi(\mathrm{A}=\pi \alpha=2.3 \%)$ [2]. Taking into account the frequency independent optical ac conductance $\mathrm{G}(\omega)$ : 


$$
G(\omega)=G_{0}=\frac{e^{2}}{4 \hbar}
$$

of a graphene monolayer [3], its $\mathrm{T}$ can be calculated by:

$$
T=\left(1+2 \pi G_{0} / c\right)^{-2}=(1+0.5 \alpha \pi)^{-2} \approx 0.977
$$

The reflectance of graphene is less than $0.1 \%$ in the visible region [4]. Even though the absorbance per graphene layer is quite high, thin graphene films have an overall high broadband transmission level, which is of high significance for transparent conductive electrodes. In addition, single- and bi-layer graphene sheets may become fully transparent as a result of Pauli blocking [5].

Compared to graphene, TMDs, like molybdenum disulfide $\left(\mathrm{MoS}_{2}\right)$, tungsten disulfide $\left(\mathrm{WS}_{2}\right)$ and molybdenum diselenide ( $\mathrm{MoSe}_{2}$ ), exhibit even higher absorption in the visible and the near infrared (NIR) range, i.e., above their respective energy band gaps, which makes this $2 \mathrm{D}$ material class an ideal candidate to act as the thinnest photo-active materials [6]. The high optical absorption in TMDs can be explained by dipole transitions between localized d states and excitonic coupling of such transitions [6,7]. Due to its high bandgap and absorption coefficient in the deep ultraviolet (UV) region, hexagonal boron nitride (h-BN) has been proposed as a potential UV photodetector [8].

\section{Technology of 2D Materials}

The key to future commercial uptake of 2D technology is the availability of large-scale material growth or synthesis methods. Chemical vapor deposition (CVD) is a well-established technique in the semiconductor industry for growing a variety of conventional materials. Today, CVD can in principle fulfill the requirement of the large-scale growth of graphene and many 2D materials of the TMD family $[9,10]$. However, the reproducible synthesis of TMDs on a large scale is still challenging, and the process technology is far from optimized. For example, it is not possible today to control exactly the number of atomic layers across a wafer or to grow monocrystalline films without grain boundaries.

The graphene CVD process is based on the decomposition of hydrocarbons on catalytic/metallic surfaces, such as copper, at temperatures above $800{ }^{\circ} \mathrm{C}$ [9]. Growth temperatures as low as $300{ }^{\circ} \mathrm{C}$ have also been achieved using a microwave plasma-assisted CVD method [11]. A second bottleneck for large-scale production of graphene devices with a low defect density is the process required to transfer the graphene films from the catalytic surface to the destined substrate. A majority of researchers use a polymer-assisted graphene transfer (e.g., polymethyl methacrylate (PMMA)), as this method is capable of handling chip or wafer-sized graphene films [12]. The method typically requires that liquids are present during the transfer step and is therefore also called wet transfer. Another approach is to use polydimethylsiloxane (PDMS) stamps, and this requires defined and controllable conditions for pressing and releasing stamps on/from the 2D surface [13]. The PDMS stamp method is classified as dry transfer. A general issue with both wet and dry transfer methods is that they often result in polymer residues on the graphene surface. In addition, transfer can induce damage or folding of the graphene films. The combined process of catalytic growth and transfer includes a step where the graphene is removed from its growth catalyst, i.e., most often copper. This can be achieved through wet etching of copper with a suitable acid or through (electrochemical) delamination. There is a high risk that this step leaves copper contaminants on the graphene that greatly reduce device performance and reliability [14]. A thorough comparison and evaluation of graphene transfer methods can be found in [15].

In 2010, Bae et al. demonstrated a concept for roll-to-roll production of graphene. They synthesized 30 inch-wide graphene films using a thermal-release tape-based transfer with good electrical and physical properties [16]. The synthesis of polycrystalline CVD graphene on $300 \mathrm{~mm}$ wafers has been demonstrated, showing more than $95 \%$ monolayer uniformity [17].

Charge carrier mobility is a good measure for the quality of graphene. So far, the highest mobility values have been reported for mechanically-exfoliated graphene, a technique not suitable for large-scale 
production. Recently, CVD graphene has been reported with Hall mobility values of $350,000 \mathrm{~cm}^{2} / \mathrm{Vs}$ at $1.6 \mathrm{~K}$ and $50,000 \mathrm{~cm}^{2} / \mathrm{Vs}$ at room temperature in devices made from single crystallites on hexagonal boron nitride [13]. These examples serve to demonstrate that chemical vapor deposition (CVD) may become a manufacturable method for graphene production in the future.

\section{Transparent Conductive Electrodes}

Photovoltaic (PV) cells, photo detectors (PDs), light emitting devices (LED), liquid crystal displays (LCD), flexible organic LEDs, flexible smart windows, bistable displays or touch screens are devices that altogether rely on electrodes with $T>80 \%$ in combination with a low sheet resistance $\left(R_{S}\right)$.

The $R_{S}$ of touch displays for example should not exceed $500 \Omega / \partial$ [18]. Applications like smart windows require $\mathrm{R}_{\mathrm{S}}$ values of about $400 \Omega$ /ð, flexible LCDs $300 \Omega /$ ð or less, flexible OLEDs about $100 \Omega /$ and high-efficiency solar cells $50 \Omega$ /ð or less [18].

State-of-the-art transparent conductive electrodes (TCEs) predominantly consist of semiconductor-based transparent conductive oxides (TCOs) that can fulfill these requirements. While indium (In) tin oxide (ITO) is the most popular representative, there are several other TCOs available, namely intrinsic indium oxide $\left(\mathrm{In}_{2} \mathrm{O}_{3}\right)$, zinc oxide $(\mathrm{ZnO})$ [19] or tin oxide $\left(\mathrm{SnO}_{2}\right)$ [20]. ITO generally obtains $T \approx 80 \%$ (at $550 \mathrm{~nm}$ ) and $10 \Omega / \partial$ on silicon dioxide $\left(\mathrm{SiO}_{2}\right)$ [21] or less than $300 \Omega / \partial$ on polyethylene terephthalate (PET), respectively [22].

ITO is comparatively expensive, and its electro-/optical properties change with the indium content and deposition technologies [17]. Although it is the most popular TCE, ITO is brittle and therefore not suitable for flexible electronic or photonic applications [20], and may be ultimately limited by the amount of indium available on the planet. Nevertheless, the first flexible organic displays have been demonstrated by Samsung at the International Consumer Electronics Show 2013 [23]. Gadgets like flexible organic thin film transistor displays for smart watches, wearable devices or consumer electronics are on the market [24]. However, future TCEs for reliable and flexible optoelectronic applications will require smart and eco-friendly high-performance TCO alternatives. Promising candidates to compete with established TCEs are thin metal (wire) films, carbon nanotubes (CNT) and graphene electrodes, which offer flexibility and efficient low- and high-frequency operation in combination with a broad wavelength transparency [25].

Graphene in particular is attracting considerable attention with its broadband transparency exceeding the performance of single-walled carbon nanotubes [26,27], metallic films [28] and ITO [21]. The fundamental limit in $R_{S}$ and $T$ in intrinsic single-layer graphene (SLG) is $6 \mathrm{k} \Omega / \partial$ [29] and 97.7\% [2], respectively. While intrinsic SLG is highly suitable to be used as a TCE in photonic devices with regards to $T, R_{S}$ remains far below the specifications for a competitive TCE. At the expense of $T, R_{S}$ can significantly be reduced by stacking SLG to reach $T>90 \%$ and $30 \Omega / \partial$ for four-layer graphene [16]. These properties beat the "minimum industrial standard" in terms of $R_{S}$ and $T$ reached by ITO films for the first time [27]. The growth of SLG with $T=95 \%$ and $7 \times 10^{5} \Omega / ð$ at $300{ }^{\circ} \mathrm{C}$ using a microwave plasma has also been successfully shown by Yamada et al., which potentially makes the graphene deposition technology compatible with low temperature processing [11]. The high mobility reported in CVD-graphene can result in $\mathrm{R}_{\mathrm{S}}$ values comparable to $\mathrm{ZnO} / \mathrm{Ag} / \mathrm{ZnO}$ [30], $\mathrm{TiO}_{2} / \mathrm{Ag} / \mathrm{TiO}_{2}$, CNTs and ITO combined with an identical or even higher transparency [29]. Nevertheless, alternative nanotechnologies, such as silver nanowire meshes [31], show promising figures of merit $(T=85 \%$ and $13 \Omega / ð$ ). These technologies, possibly in combination with graphene as the base material, may lead to superior performance of pure graphene-based TCEs.

\section{Photodetectors}

Photodetectors (PDs) typically consist of p-n junctions, i.e., one n-doped and a complementarily p-doped area that form a space-charge region at the interface. Crystalline silicon (x-Si) p-n junctions cover a spectral bandwidth from the UV $(\lambda>190 \mathrm{~nm})$ to the NIR $(\lambda<1100 \mathrm{~nm})$ spectrum and are the most conventional PDs available. Typical sensor specifications are: dark currents of tens of $\mathrm{pA}$, 
rise times below $1 \mu \mathrm{s}$, a maximum spectral response (SR) in the range of $600 \mathrm{mAW}^{-1}$ and cutoff frequencies in between 20 and $30 \mathrm{MHz}$. The SR is an area independent relative measure of the wavelength-dependent photocurrent. The position and amplitude of the peak SR can vary by orders of magnitude, depending on technological parameters like junction depth or doping concentrations. The main applications of $x$-Si sensors are in the fields of digital imaging systems and optical switches. Si avalanche photodiodes (APDs) are a special type of PD, which are optimized for low light level detection. Their bandwidth commonly ranges from $320 \mathrm{~nm}-1150 \mathrm{~nm}$. InGaAs pin-diodes are detectors used in optical communication systems or power meters, covering in particular NIR bands in between $900 \mathrm{~nm}$ and $1700 \mathrm{~nm}$. Sensitivities of $\sim 1.1 \mathrm{~A} / \mathrm{W}$ or less are typical in such diodes. In the past, germanium (Ge)-based detectors have been used as alternatives to low-cost InGaAs PDs. These detectors celebrated a rebirth in integrated optoelectronics, as it became possible to deposit $\mathrm{Ge}$ on $\mathrm{Si}$ directly [32]. Recently, tin-doped Ge films (GeSn) are being investigated as alternative semiconductors with reduced direct band gaps [33]. High-stability GaAsP diodes with sensitivities ranging from the near-UV $(280 \mathrm{~nm})$ to $680 \mathrm{~nm}$ and GaP Schottky diodes with high UV sensitivities $(190 \mathrm{~nm}-550 \mathrm{~nm})$ are exotic material examples that expand the wide range of active absorbers available for PDs. However, every single absorber is optimized only for a specific wavelength regime. Up to now, there is no "all-in-one" PD commercially available that covers a bandwidth including the UV-regime below 190 $\mathrm{nm}$, the visible and the IR spectrum above $1150 \mathrm{~nm}$ at the same time. The synthesis of TMDs and novel 2D materials might become one of the key enabling technologies in the near future to extend the spectral bandwidth of existing photonic devices. Graphene in particular plays a significant role in research towards extending the spectral bandwidth of PDs due to its almost linear absorption of photons over the complete electromagnetic spectrum. In the following section, the performance, especially the SR of PDs and optical waveguides, of photonic devices based on 2D materials is reviewed.

\subsection{Graphene Photodetectors}

Graphene offers highly efficient tuning of the carrier type and density, which can be utilized to induce $p-n$ junctions, e.g., by electrostatic gating [34]. Other possibilities to create $p-n$ junctions in graphene or related 2D materials are chemical doping [35] or by exploiting the work function difference between the intrinsic material (e.g., $\Delta \mathrm{W}=4.45 \mathrm{eV}$ for graphene [36]) and metal contacts [37-39].

Examples of mono- and bi-layer graphene photodetectors with electrostatically-tunable $\mathrm{p}-\mathrm{n}$ junctions were reported by Lemme et al. [34]. Here, the graphene p-n junctions were formed with a dual gate configuration, i.e., a local top gate electrode and a global back gate (Figure $1 \mathrm{a}, \mathrm{b}$ ). The device thus allowed tuning the carrier type and density under the top gate independently from the graphene outside the top gate region (Figure 1c). Thus, operation in four different regimes is possible, i.e., with $\mathrm{p}-\mathrm{n}, \mathrm{p}-\mathrm{p}^{+}, \mathrm{n}-\mathrm{p}$ and $\mathrm{n}-\mathrm{n}^{+}$junctions at the edges of the top gate (Figure 1d). A photo responsivity of $\sim 1.4 \mathrm{mAW}^{-1}$ was demonstrated with scanning photocurrent measurements $(\lambda=532 \mathrm{~nm}, \mathrm{P}=30 \mu \mathrm{W})$. It was further shown that the photocurrent was highest when the devices were operated as $p-n$ or $\mathrm{p}$ junctions. This was consistent with theory and could be described by the photo-thermoelectric effect (PTE). Similar investigations on dual-gated monolayer and bilayer graphene $\mathrm{p}-\mathrm{n}$ junctions were reported by Gabor et al. [40]. They concluded that nonlocal hot carrier transport with a long-lived and spatially-distributed hot carrier population dominates the intrinsic photoresponse in graphene over the photovoltaic effect [40]. Subsequent experimental and theoretical work supports that the efficiency of lattice cooling in graphene is quite poor, so that hot carriers are responsible for nonlocal transport [41-43]. The highest SR for a graphene $\mathrm{p}-\mathrm{n}$ junction reported so far is $10 \mathrm{mAW}^{-1}$ at $514.5 \mathrm{~nm}$ [44]. This device is similar to those reported in [34] and [40], but optimized, as the edge contacted graphene additionally contains a suspended area in the device center. 


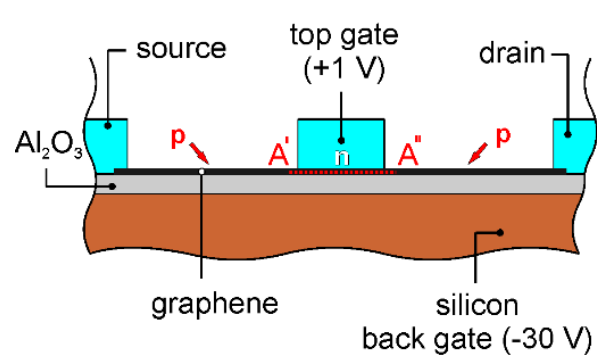

(a)

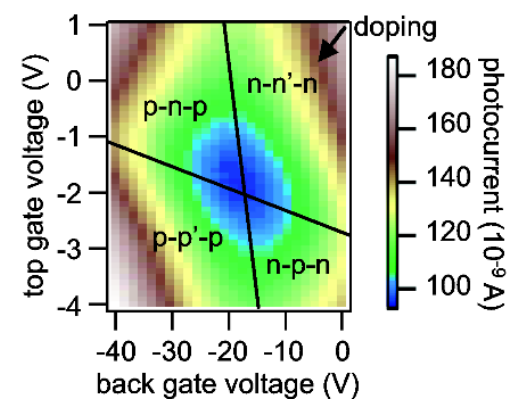

(c)

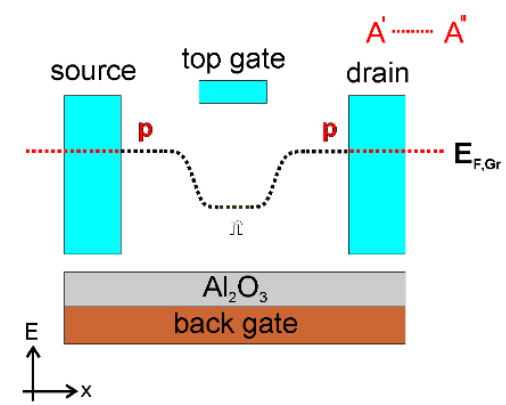

(b)

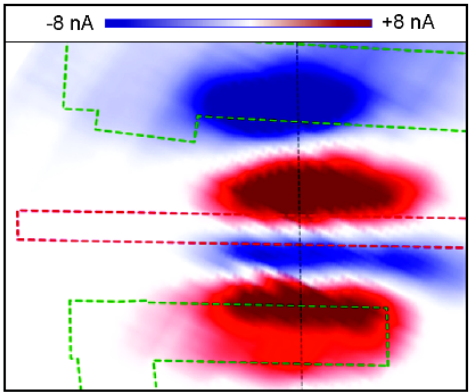

(d)

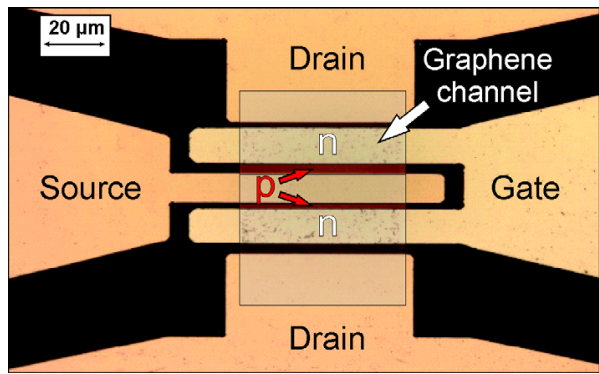

(e)

Figure 1. (a) Schematic of a top- and back-gate tunable graphene phototransistor; (b) Schematic of the band structure of a symmetric phototransistor with a top and a back gate; (c) Drain current (color scale) as a function of the back and top gate voltages. The black lines indicate the location of the charge neutrality (Dirac) point of the global (back gated) and local (top gated) device. The phototransistor can be operated in four distinct regions (i.e., p-n-p etc.); (d) Photocurrent map of a lateral phototransistor. The photocurrent is highest at the location of $\mathrm{p}-\mathrm{n}$ junctions, i.e., next to the metal contacts and the top gate region (modified from [34]); (e) Optical micrograph of a graphene phototransistor. Examples for $\mathrm{p}$ and $\mathrm{n}$ regions are indicated.

Fixed p-n junctions can be readily obtained in metal-graphene-metal assemblies, which have been used with back gate electrodes to demonstrate photocurrents [45-48]. Recently, Withers et al. substituted metal electrodes with $\mathrm{FeCl}_{3}$-intercalated multilayer graphene to assemble an "all-graphene"-based PD that generates a PTE-induced photovoltage of $\sim 0.1 \mathrm{VW}^{-1}$ [49]. Mueller et al. demonstrated a graphene-metal PD for visible and NIR wavelengths with a bandwidth larger than $40 \mathrm{GHz}$, an internal quantum efficiency (IQE) of 10\% and an external quantum efficiency (EQE) of $0.5 \%$ [37]. This device performed well as an optical data link up to $10 \mathrm{Gbit} / \mathrm{s}$. An asymmetric metal-graphene-metal configuration (i.e., two different metals) was used to break the mirror symmetry of the internal electric-field profile to induce the photovoltaic effect (PVE). The two metals effectively doped the graphene differently by charge transfer as a result of work function differences at the metal-graphene interfaces (Figure 2). We note that the discussion about the underlying mechanisms of the photocurrent in metal-graphene junctions is still on-going [50]. 
a)

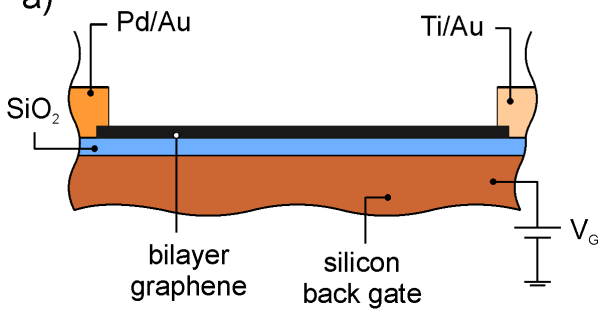

b)

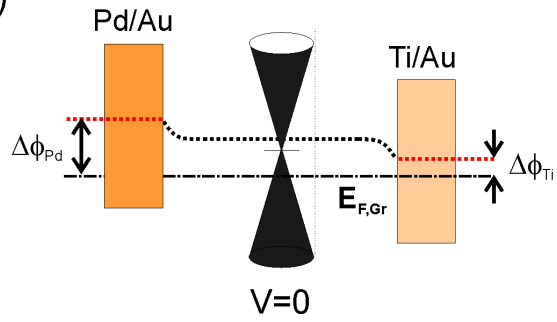

Figure 2. (a) Schematic of a bilayer graphene photodetector (PD) with asymmetric metal contacts; (b) schematic of the band structure of the device in (a) (after [37]).

Graphene PDs have been integrated into silicon waveguides in a process compatible with $\mathrm{Si}$ complementary metal oxide semiconductor (CMOS) technology for potential applications as on-chip optoelectronic couplers [51,52] or modulators [53]. This concept was further explored by Schall et al., who successfully demonstrated waveguide-integrated CVD graphene PDs with a bandwidth of $41 \mathrm{GHz}$ and an extrinsic response of $16 \mathrm{mAW}^{-1}$ [54]. The detection of data signals up to $50 \mathrm{Gbit} \cdot \mathrm{s}^{-1}$ is comparable to the performance of state-of-the-art germanium-based Si waveguide-coupled PDs [32,55]. A similar graphene/Si waveguide-integrated PD by Wang et al. exhibits a sensitivity of $0.13 \mathrm{mAW}^{-1}$ at mid-IR wavelengths $(\lambda=2.75 \mu \mathrm{m})$. Here, the SR was described by a combination of the PTE and the PVE [25].

Schottky diodes represent an alternative to p-n junctions as photodetectors. Schottky diodes consist of metal-semiconductor junctions that can typically be operated at higher frequencies than semiconductor $p-n$ junctions. PDs require a depletion region where electrical charge can be generated and extracted under reverse bias conditions that separate electrons and holes. Simple vertical Schottky junctions can be obtained by placing graphene on suitable semiconductors (Figure 3a,b). Chen et al. presented electrical measurements on graphene/Si Schottky diodes with a junction area of $92 \mu \mathrm{m}^{2}$ [56]. They achieved an ideality factor of $n=4.89$ at room temperature, which is a quality indicator, where $n=1$ implies that the device can be modeled by the ideal Shockley diode equation. State-of-the-art bulk semiconductor PDs achieve values in the range of $n=1-2$. We reported large area graphene/Si Schottky diodes by transferring large-area $\left(2 \times 4 \mathrm{~cm}^{2}\right)$ single-layer CVD-grown graphene onto n-type $\mathrm{Si}$ (Figure 1c, black solid line) [57], demonstrating the integration of 2D materials into the existing Si platform. The simple, yet scalable fabrication process yielded devices with peak sensitivity of $270 \mathrm{mAW}^{-1}$ at $992 \mathrm{~nm}$ and an ideality factor of approximately 1.5. When fabricated on p-type Si (Figure 3c, red dashed line), the devices do not exhibit rectification, because the graphene is also p-type when measured in ambient air due to humidity [58] and/or other adsorbates. Figure 3d compares the SR of a graphene/n-Si Schottky diode with that of a commercial x-Si p-n PD. The absolute response of the graphene/Si diode reaches approximately $50 \%$ of the reference values. This may be further improved by optimizing the contact resistance between the SLG and the x-Si substrate, a general issue with graphene-based devices [59]. An additional feature is worth mentioning: the SR of the commercial PD vanishes for photon wavelengths $\lambda>1200 \mathrm{~nm}$ due to the electronic band gap of Si. The graphene/Si heterodevice, in contrast, clearly remains sensitive in the NIR region (inset in Figure 3d). In that regime, the absorption in SLG enables detection, albeit at much lower responsivity values due to the monolayer absorption of approximately $2.3 \%$. An optimized graphene/Si Schottky diode was reported by An et al. with a junction area of $25 \mathrm{~mm}^{2}$ on n-type silicon [60]. Here, three-layer graphene was doped by pyrenecarboxylic acid (PCA). The device reached a maximum SR of $\sim 435 \mathrm{mAW}^{-1}$, which corresponds to an IQE of $\sim 65 \%$ at a peak wavelength in the range of $850 \mathrm{~nm}-900 \mathrm{~nm}$. This performance is comparable to state-of-the-art bulk x-Si PDs. The device remained stable even after 10 days and could withdraw 1000 light-switching cycles with a current variation of $\pm 2.5 \%$ (dark current) and $\pm 5 \%$ (photocurrent) without noticeable drift phenomena. A similar non-doped SLG device showed a maximum SR of $\sim 320 \mathrm{mAW}^{-1}$. Kim et al. proposed a graphene/Si heterojunction diode as a chemical 
sensor [61]. They utilized the fact that the graphene work function can be effectively modified through exposure to liquids or gases. This modulates the Schottky barrier height of the diodes and, hence, their resistance. The authors demonstrated considerable long-term stability and repeatability and suggested such devices as a platform for applications in gas, bio- and environmental sensing.

a)

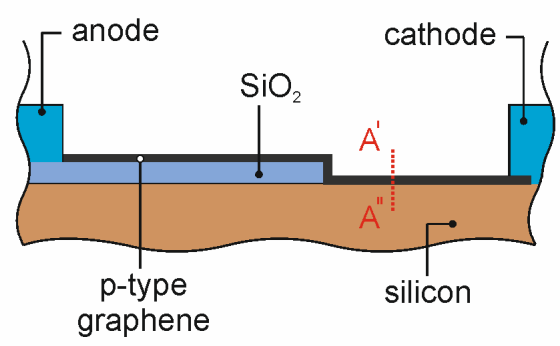

c)

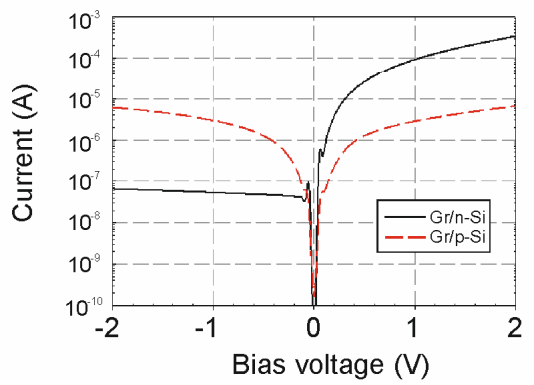

b)

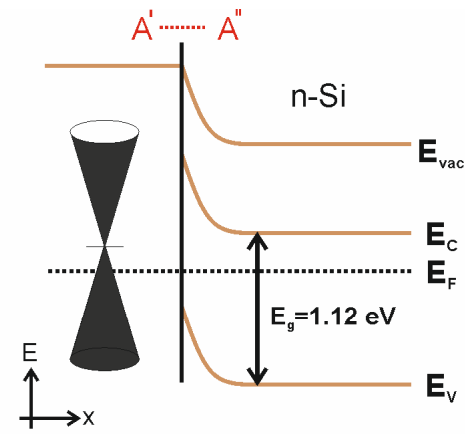

d)

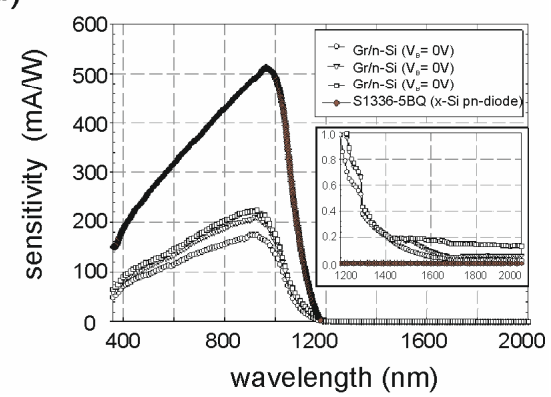

Figure 3. (a) Schematic of a graphene/Si heterojunction PD; (b) schematic of the band structure of the device in (a); (c) I-V curves of graphene-Si diodes on n-type (black solid line) and p-type (red dashed line) Si substrates; (d) comparison of the bias-dependent spectral response of a graphene/Si PD with a state-of-the-art bulk p-n junction Si PD. Inset: magnification of the spectral response in the IR region, where the response is entirely due to the graphene [57].

While the extrinsic response of graphene-based devices is generally below $\sim 1 \mathrm{AW}^{-1}$, which is commonly reached by non-avalanche Ge detectors, the IQE of a variety of reported graphene PDs is quite high, with values reaching $30 \%-60 \%[44,45]$. This indicates that the response is not limited by the intrinsic performance of graphene, but rather by non-optimized device layouts or by the electrical contacts. In addition, carrier multiplication in graphene may improve the quantum efficiencies in graphene-based devices to over 100\%, if specific conditions are fulfilled $[43,62,63]$.

In addition to these efforts, different strategies have been proposed and demonstrated to enhance the light absorption in graphene-based PDs, which include graphene nanostructures [64], chemical doping [65], plasmonic nanostructures in graphene [66] and the integration of graphene into photonic cavities $[67,68]$. In graphene, enhancement factors of 15 have been achieved using plasmonic nanostructures [69]. Other strategies combine graphene with different nanostructured materials to form graphene-based hybrid materials. Some hybrid materials that have been proposed include polymers [70], plasmonic nanostructures on graphene [71] and one-dimensional (1D) nanorods [72] or zero-dimensional (0D) quantum dots (QDs) [73]. The advantage of graphene hybrids is that the deposited materials do not only act as light harvesters, but they also provide interfaces or hetero-junctions, which can facilitate the separation of excitons, thereby extending the functionality of graphene-based optoelectronic devices. QDs are photosensitive nanostructures with tunable spectral properties, e.g., by controlling their size and shapes. This gives an advantage over other nanostructures, because desired optical properties can be achieved over a broad range of the electromagnetic 
spectrum. Hybrid graphene-QD phototransistors with ultrahigh gain (i.e., the number of charged carriers generated per incident photon) using colloidal $\mathrm{PbS}$ quantum dots have demonstrated photoresponsivity of up to $10^{7} \mathrm{AW}^{-1}[74,75]$. This high value was attributed to efficient carrier generation in the QDs and subsequent charge transfer to graphene. Flexible infra-red PDs based on CVD graphene and PbS QDs have also exhibited high photoresponsivity [76]. Ligand-capped colloidal $\mathrm{PbS}$ QDs in hybrid graphene-QD phototransistors reached a photosensitivity of $10^{9} \mathrm{AW}^{-1}$ [77]. This was attributed to efficient charge transfer between the graphene and the QDs through the optimized thickness of the capping ligands. Devices with layered and bulk heterojunctions with hybrid graphene-PbSe QD materials have also been studied to investigate the influence of heterojunctions on the photoresponsivity [78].

\subsection{TMD Photodetectors}

The 2D TMDs, like $\mathrm{MoS}_{2}$, are very promising for photonic and optoelectronic applications. They exhibit even higher absorption coefficients than graphene, even though they are typically limited in their spectral bandwidth by their electronic band gaps. In this section, we discuss TMD-based p-n diodes and heterojunction devices of both TMD-bulk semiconductors and exclusively of 2D materials.

Examples of TMD PDs include lateral symmetric (reverse) Schottky diode configurations, which utilize the built in potentials at the $\mathrm{MoS}_{2}$-metal contacts to drive photocurrents $[79,80]$. Sanchez-Lopez et al. reported impressive responsivity of $880 \mathrm{mAW}^{-1}$ at $561 \mathrm{~nm}$ from an exfoliated $\mathrm{MoS}_{2}$ flake [79]. This number was calculated from photocurrents measured under ultra-low illumination intensities of $24 \mu \mathrm{Wcm}^{-2}$. However, the noise equivalent power (NEP) of $1.8 \times 10^{-15} \mathrm{WHz}^{-1 / 2}$ in the $\mathrm{MoS}_{2}$ photoconductor is considerably lower compared to state-of-the-art $\mathrm{Si}$ avalanche photodetectors $\left(3 \times 10^{-14} \mathrm{WHz}^{-1 / 2}\right)$ [81]. Zhang et al. carried out a similar experiment on CVD-grown $\mathrm{MoS}_{2}$ and showed an even more impressive responsivity of $2200 \mathrm{AW}^{-1}$ in a vacuum and $780 \mathrm{AW}^{-1}$ in ambient air [80]. The authors attributed this difference mainly to enhanced carrier recombination in ambient air. In fact, environmental factors often influence the behavior and performance of TMD PDs. Kufer et al. have demonstrated an encapsulated $\mathrm{MoS}_{2}$ detector that is independent of the ambient air, but becomes highly tunable through an electrostatic gate with responsivity ranging from $10-10^{4} \mathrm{AW}^{-1}$ [82]. A more complex structure was reported by Pospischil et al., who used two independent gate electrodes to induce a lateral, tunable p-n junction in single-layer exfoliated tungsten diselenide ( $\mathrm{WSe}_{2}$ ) [83]. The $\mathrm{WSe}_{2}$ flake was electrostatically doped to act either as a solar cell, a PD or an LED with a power conversion efficiency of $\sim 0.5 \%$ and an electroluminescence efficiency of $\sim 0.1 \%$. In PD mode, a responsivity of $16 \mathrm{mAW}^{-1}$ was obtained.

Vertical p-n junctions can be fabricated by stacking 2D materials on bulk materials or on other 2D materials, similar to the graphene/Si devices described in Section 4.1 [57]. While Lopez-Sanchez et al. investigated exfoliated $\mathrm{MoS}_{2}$ flakes on $\mathrm{Si}$ [84], Yim et al. demonstrated the fabrication of large-area CVD $\mathrm{MoS}_{2} /$ Si devices, where a sputtered Mo film was sulfurized in a highly controllable and reproducible manufacturing process [85]. Multispectral measurements showed both the absorption signatures of $\mathrm{Si}$ and bulk $\mathrm{MoS}_{2}$, with the sensitivity bandwidth limited by the Si band gap [85].

Recently, several groups have reported heterostructures based entirely on 2D materials, also referred to as van der Waals (vdW) heterostructures. Furchi et al. showed results from an atomically-thin p-n diode consisting of exfoliated flakes of monolayer $\mathrm{MoS}_{2}$ and monolayer $\mathrm{WSe}_{2}$ [86]. This device exhibited a responsivity of $11 \mathrm{mAW}^{-1}$ at $650 \mathrm{~nm}$. A very similar device reported by Lee $e t$ al. exhibited a responsivity of $2 \mathrm{mAW}^{-1}$ at $532 \mathrm{~nm}$ [87]. The authors concluded that the photocurrent is dominantly caused by the PV rather than the PTE effect. A similar device layout with identical materials was chosen by Cheng et al.; but here, one of the materials $\left(\mathrm{WSe}_{2}\right)$ was grown by CVD, and an exfoliated $\mathrm{MoS}_{2}$ flake was used [88]. This device exhibited an EQE of up to 12\%. A gallium telluride $(\mathrm{GaTe})-\mathrm{MoS}_{2}$ vdW heterodiode by Wang et al. displayed a very remarkable responsivity of over $20 \mathrm{AW}^{-1}$ [89]. A combination of graphene, h-BN and a TMD by Britnell et al. consisted of a h-BN/Gr/ $\mathrm{WS}_{2} / \mathrm{Gr} / \mathrm{h}-\mathrm{BN}$ stack [90]. This multilayer vertical device acts as a flexible PD or solar 
cell and was fabricated on a polyethylene terephthalate (PET) film. A responsivity of $0.1 \mathrm{AW}^{-1}$ was achieved at $633 \mathrm{~nm}$ with an EQE of $30 \%$.

In general, the area of research on van der Waals heterostructures is in a very early stage. Given the recent advances in the CVD growth of 2D materials, it seems now possible to scale up the synthesis of 2D material-based heterostructures with good control of the layer thickness and quality [91]. Han et al. have developed an atmospheric pressure CVD technique to grow in-plane heterostructures of h-BN and graphene [92]. Figure 4a shows schematics and optical micrographs of the continuous growth of these heterostructures. They mention that by controlling the growth conditions, one can obtain a relatively sharp interface in such a structure. Gao et al. developed a CVD method to controllably grow vertical and lateral heterostructures of h-BN and graphene on $\mathrm{Cu}$ foils [93]. They used a novel temperature-triggered reaction process to selectively grow such heterostructures. Figure $4 \mathrm{~b}$ depicts the growth strategy followed by the authors, where they have used benzoic acid as a carbon source, which decomposes to $\mathrm{CO}_{2}$ and other hydrocarbons at temperatures higher than $500^{\circ} \mathrm{C}$. The released $\mathrm{CO}_{2}$ was found to etch $\mathrm{h}-\mathrm{BN}$ at temperatures above $900{ }^{\circ} \mathrm{C}$, thus exposing the $\mathrm{Cu}$ surface for lateral growth of graphene. At lower temperatures, $\mathrm{h}-\mathrm{BN}$ was not etched by $\mathrm{CO}_{2}$, and graphene was grown directly on its surface. Their work is quite promising for the fabrication of high performance graphene-based devices. Successful large-area growth of TMDs, like $\mathrm{MoS}_{2}, \mathrm{WS}_{2}, \mathrm{MoSe}_{2}$ and $\mathrm{WSe}_{2}$, using CVD has motivated researchers to grow these materials simultaneously or on other 2D materials for heterostructures. Shi et al. have synthesized $\mathrm{MoS}_{2}$ /graphene heterostructures using ammonium thiomolybdate as a precursor and CVD graphene on $\mathrm{Cu}$ foil as a substrate [94]. They were able to achieve single crystalline hexagonal flakes of $\mathrm{MoS}_{2}$ with a lateral size ranging from several hundred nanometers to several micrometers. Figure $4 \mathrm{c}$ shows a schematic of the growth process and a representative AFM phase image revealing the presence of graphene and $\mathrm{MoS}_{2}$ on $\mathrm{Cu}$ foil. Lin et al. have demonstrated the direct synthesis of $\mathrm{MoS}_{2}, \mathrm{WS}_{2}$ and h-BN on epitaxial graphene grown on $\mathrm{SiC}$ substrates [95]. Figure $4 \mathrm{~d}$ shows the atomic arrangement of the heterostructures as revealed by transmission electron microscope (TEM) investigations. By performing detailed structural and morphological studies, they found that the properties of fabricated heterostructures depend significantly on the underlying graphene template. It was observed that wrinkles and defects on the graphene surface act as nucleation sites for the lateral growth of overlayers. The photosensor based on such a structure generated a power-dependent photocurrent ranging from $150-550 \mathrm{nA}$ at $V_{d s}=1 \mathrm{~V}$ with a laser power ranging from 4-40 $\mu \mathrm{W}$ under a constant excitation wavelength of $488 \mathrm{~nm}$. The device exhibited a photoresponsivity of $40 \mathrm{mAW}^{-1}$ with a $15 \mu \mathrm{m}$-long channel at $V_{d s}=1 \mathrm{~V}$ and $V_{b g}=0 \mathrm{~V}$. Further, they demonstrated an improvement of about $10^{3}$ in the photoresponse of $\mathrm{MoS}_{2}$ grown on graphene as compared to bare $\mathrm{MoS}_{2}$.

Gong et al. reported a one-step growth strategy for fabricating high quality vertically-stacked and in-plane heterostructures based on single-layer $\mathrm{MoS}_{2}$ and $\mathrm{WS}_{2}$ by controlling the growth temperature [96]. It was found that a vertically-stacked bilayer consisting of a $\mathrm{WS}_{2}$ monolayer grown epitaxially on a $\mathrm{MoS}_{2}$ monolayer is preferred at high temperatures, whereas lateral epitaxy of $\mathrm{WS}_{2}$ at $\mathrm{MoS}_{2}$ edges is dominating at low temperatures of around $650^{\circ} \mathrm{C}$. Figure $4 \mathrm{e}$ shows the schematic and optical images of vertically-stacked and in-plane heterostructures of single-layered $\mathrm{WS}_{2}$ and $\mathrm{MoS}_{2}$. A strong interlayer excitonic transition in vertically-stacked layers and a strong photoluminescence enhancement with the formation of intrinsic $p$-n junctions in lateral structures attested the formation of atomically-sharp and clean interfaces. The devices based on lateral heterostructures were found to exhibit a photovoltaic effect under illumination with an open loop voltage of $0.12 \mathrm{~V}$ and a closed loop current of $5.7 \mathrm{pA}$ without external gating effects. Li et al. reported a two-step growth strategy for fabricating epitaxial $\mathrm{WSe}_{2} / \mathrm{MoS}_{2}$ heterojunctions by sequential CVD of $\mathrm{WSe}_{2}$ and $\mathrm{MoS}_{2}$ [97]. First, single crystalline $\mathrm{WSe}_{2}$ monolayers were prepared, and then, $\mathrm{MoS}_{2}$ growth was performed on these monolayers separately. Figure $4 \mathrm{f}$ shows the schematic of the sequential growth of monolayer $\mathrm{WSe}_{2} / \mathrm{MoS}_{2}$ in-plane heterostructures along with an optical micrograph showing the distinct optical contrast between the two. They confirmed the intrinsic $p-n$ junction properties of the heterostructures by measuring the depletion width, photoresponse, rectifying behavior and PVE in the devices made 
out of these structures. A PVE with an open circuit voltage of $0.22 \mathrm{~V}$ and a short circuit current of $7.7 \mathrm{pA}$ was measured under white light illumination at a power density of $1 \mathrm{~mW} / \mathrm{cm}^{2}$. The power conversion efficiency of the device was calculated to be around $0.2 \%$ with a small fill factor (FF) of 0.39 , which might be due to the high equivalent series resistance of the intrinsic TMD layers.

a) i)

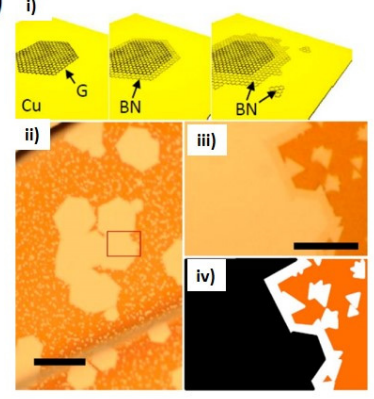

c) i)

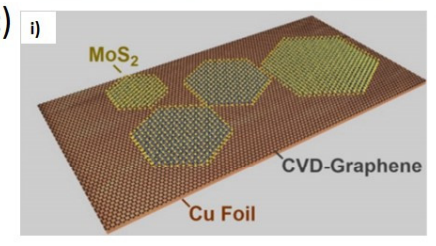

d)

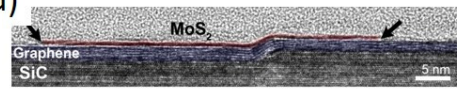

e) i) $\quad 850^{\circ} \mathrm{C}$

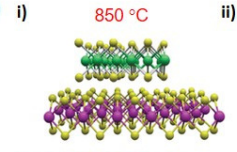

Vertical WS $2 / \mathrm{MoS}_{2}$ bilayer

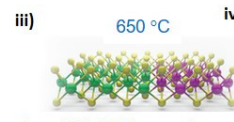

In-plane $\mathrm{WS}_{2} / \mathrm{MoS}_{2}$ monolayer
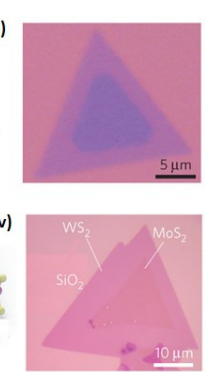

b)
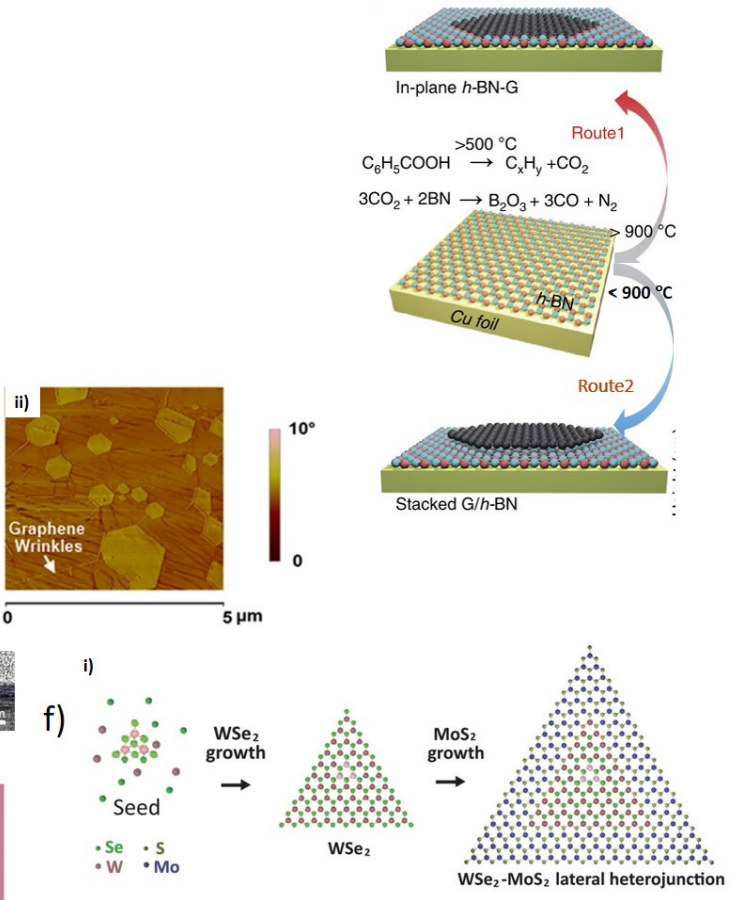

ii)

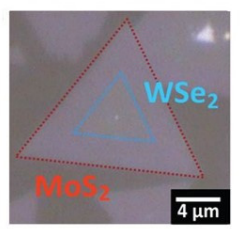

Figure 4. (a) Schematic of the continuous growth of graphene/hexagonal boron nitride (h-BN) heterostructures on $\mathrm{Cu}$ foil (i). Low (scale bar is $50 \mu \mathrm{m}$ ) (ii) and high magnification (scale bar is $10 \mu \mathrm{m}$ ) (iii) image of graphene/h-BN heterostructures on oxidized Cu substrate; (iv) false color image. Black, white and brown regions indicate graphene, $\mathrm{h}-\mathrm{BN}$ and bare $\mathrm{Cu}$ regions in panel (iii), respectively [92]; (b) Schematic illustration of the temperature-triggered switching growth between in-plane and vertical graphene/h-BN heterostructures, depicted by Route 1 and Route 2, respectively [93]; (c) Schematic of hexagonal $\mathrm{MoS}_{2}$ layers grown on a CVD graphene template (i). AFM phase image of $\mathrm{MoS}_{2}$ grains on graphene (ii) [94]; (d) Cross-sectional high resolution TEM of $\mathrm{MoS}_{2}$ layer grown on epitaxial graphene [95]; (e) Schematic and optical image of the vertically-stacked heterostructure synthesized at $850{ }^{\circ} \mathrm{C}$ (i, ii) and lateral $\mathrm{WS}_{2} / \mathrm{MoS}_{2}$ heterostructure synthesized at $650{ }^{\circ} \mathrm{C}$ (iii, iv) [96]; (f) Schematic illustration of the sequential growth of the monolayer in-plane $\mathrm{WSe}_{2} / \mathrm{MoS}_{2}$ heterostructures (i) and optical micrograph of the heterostructures depicting the contrast between two layers [97]. Reproduced with permission from: (a) [92] copyright ${ }^{\oplus} 2013$ American Chemical Society; (b) [93] copyright ${ }^{\oplus} 2015$ Macmillan Publishers Ltd.; (c) [94] copyright ${ }^{\circledR} 2012$ American Chemical Society; (d) [95] copyright ${ }^{\odot}$ 2014 American Chemical Society; (e) [96] copyright ${ }^{\odot} 2014$ Macmillan Publishers Ltd.; and (f) [97] copyright $^{\circledR} 2015$ American Association for the Advancement of Science.

Table 1 summarizes the experimental results from 2D material photonic devices as described in this review. In particular, the number of integrated layers, the device fabrication technology and electro-/optical benchmark parameters EQE, IQE, photo conversion efficiency (PCE) and SR, are listed 
where reported. The bold SR entries represent competitiveness and improvements of 2D detectors compared to state-of-the art Si PDs with regard to the absolute SR or the frequency bandwidth.

Table 1. Summary of literature data for $2 \mathrm{D}$ material-based photonic devices. The table contains the layer thickness, 2D material fabrication technology and electro-/optical benchmark parameters (external quantum efficiency (EQE), internal quantum efficiency (IQE), photo conversion efficiency (PCE) and spectral response (SR)), where reported. SLG, single-layer graphene.

\begin{tabular}{|c|c|c|c|c|c|}
\hline Graphene Devices & Layer No. & Technology & EQE/IQE/PCE (\%) & Max. SR (mAW $\left.{ }^{-1}\right)$ & Ref. \\
\hline \multirow{3}{*}{$\begin{array}{c}\text { Graphene/Si } \\
\text { Schottky junction }\end{array}$} & SLG & \multirow{5}{*}{ CVD } & - & $\begin{array}{c}270 \text { at } 992 \mathrm{~nm} \\
\mathbf{0 . 1 7} \text { at } 2000 \mathrm{~nm}\end{array}$ & [57] \\
\hline & 3LG p-doped & & IQE $>65$ & $435(850-900 \mathrm{~nm})$ & {$[60]$} \\
\hline & SLG & & - & $320(850-900 \mathrm{~nm})$ & {$[60]$} \\
\hline Graphene/Si-waveguide & SLG on $\mathrm{Si}$ & & - & 0.13 at $2.75 \mu \mathrm{m}$ & [98] \\
\hline $\begin{array}{l}\text { Graphene/GaN } \\
\text { Schottky diode }\end{array}$ & SLG & & - & $0.23 \mathrm{AW}^{-1}$ at $360 \mathrm{~nm}$ & [99] \\
\hline Graphene on $\mathrm{SiO}_{2} / \mathrm{Si}$ & Bilayer & \multirow{4}{*}{ Exfoliated flake } & - & 1.3 at $0.292 \mathrm{THz}$ & [100] \\
\hline Metal-graphene-metal & Bilayer & & $\begin{aligned} \mathrm{EQE} & =0.5 \\
\mathrm{IQE} & =10\end{aligned}$ & $\begin{array}{l}6.1 \text { at } 1550 \mathrm{~nm} \\
\text { (VIS-NIR) }\end{array}$ & [37] \\
\hline \multirow{3}{*}{$\begin{array}{c}\text { Graphene } \\
\text { p-n-junction }\end{array}$} & SLG (electr. Doping) & & - & $\begin{array}{l}1.5 \text { at } 532 \mathrm{~nm} \\
(P=30 \mu W)\end{array}$ & [34] \\
\hline & Bilayer & & - & 5 at $850 \mathrm{~nm}(T=40 \mathrm{~K})$ & {$[40]$} \\
\hline & Trilayer & $\begin{array}{l}\text { Exfoliated, edge } \\
\text { contacted }\end{array}$ & - & 10 at $514.5 \mathrm{~nm}$ & [44] \\
\hline Flexible organic PDs & $\begin{array}{c}\text { Graphene/PEDOT:PSS } \\
\text { ink }\end{array}$ & Spray coating & - & $0.16 \mathrm{AW}^{-1}$ at $500 \mathrm{~nm}$ & [101] \\
\hline TMD Devices & Layer No. & Technology & EQE/IQE/PCE (\%) & Max. SR (mAW $\left.{ }^{-1}\right)$ & Ref. \\
\hline $\begin{array}{c}\mathrm{MoS}_{2} \text { on } \mathrm{SiO}_{2} \\
\text { photoconductor }\end{array}$ & SL & \multirow{4}{*}{ Exfoliated flakes } & - & $\mathbf{8 8 0} \mathbf{A} / \mathbf{W}$ at $561 \mathrm{~nm}$ & [79] \\
\hline $\mathrm{WSe}_{2}$ & SL (electr. doped) & & $\mathrm{PCE}=0.5$ & $\begin{array}{c}\text { Electroluminescent at } \\
1.547 \mathrm{eV}\end{array}$ & [83] \\
\hline $\mathrm{WSe}_{2} / \mathrm{MoS}_{2}$ & SL & & $\mathrm{EQE}=2.1$ & 11 at $650 \mathrm{~nm}$ & {$[86]$} \\
\hline h-BN/Gr/WS $/$ /Gr/h-BN & SL & & $\mathrm{EQE}=30$ & 0.1 at $633 \mathrm{~nm}$ & [90] \\
\hline $\begin{array}{c}\mathrm{MoS}_{2} / \mathrm{Si} \mathrm{Schottky} \\
\text { junction }\end{array}$ & $\begin{array}{l}8.26 \mathrm{~nm} \\
\text { (12 layer) }\end{array}$ & & - & 8.6 & [85] \\
\hline $\begin{array}{l}\mathrm{WSe}_{2}-/ \mathrm{MoS}_{2} \\
\text { pn-junction }\end{array}$ & SL p-n diode & CVD & $\mathrm{EQE}=2.1$ & 11 at $650 \mathrm{~nm}$ & [86] \\
\hline $\begin{array}{l}\mathrm{MoS}_{2} / \text { graphene } \\
\text { photoconductor }\end{array}$ & SLG & & $\mathrm{IQE} \approx 15$ & $10^{7}$ at $650 \mathrm{~nm}$ & [102] \\
\hline
\end{tabular}

\section{Conclusions}

In this work, photonic devices that comprise graphene and other two-dimensional materials and their performance have been reviewed and compared to benchmarks of state-of-the-art bulk optoelectronic devices. Moreover, physical mechanisms that enable photodetection have been discussed. We presented challenges of existing 2D material process technologies, namely contaminations, reproducibility and scalability. A variety of 2D photonic devices that show additional functionalities compared to state-of-the-art bulk devices was presented. Some of the intrinsic properties of graphene, such as the absence of an electronic band gap, carrier multiplication and high carrier mobility, suggest applications as broadband and high speed photodetectors, which have been demonstrated in several instances. Even though the monoatomic nature of graphene presents a limitation in the absorbance, many promising solutions are being pursued. A brief overview of heterostructures of bulk and 2D materials, such as hybrid graphene/Si and $\mathrm{MoS}_{2} / \mathrm{Si}$ diodes, has been given. Finally, heterojunctions made up entirely of 2D materials have been reviewed, taking into account the recent advances in large-scale fabrication of 2D crystals. The multitude of reports, the excellent performance and the rapid progress in the field are quite encouraging. Nevertheless, there are severe challenges towards a manufacturable, reliable and reproducible large-scale 2D technology for optoelectronics. We remain confident that these can be met with time and substantial efforts. 
Acknowledgments: Funding from the European Research Council (ERC, 307311) and the German Research Foundation (DFG LE 2440/1-1, GRK 1564) is gratefully acknowledged.

Author Contributions: A.B., S.K. and M.C.L. wrote the paper.

Conflicts of Interest: The authors declare no conflict of interest.

\section{References}

1. Novoselov, K.S.; Fal'ko, V.I.; Colombo, L.; Gellert, P.R.; Schwab, M.G.; Kim, K. A roadmap for graphene. Nature 2012, 490, 192-200. [CrossRef] [PubMed]

2. Nair, R.R.; Blake, P.; Grigorenko, A.N.; Novoselov, K.S.; Booth, T.J.; Stauber, T.; Peres, N.M.R.; Geim, A.K. Fine structure constant defines visual transparency of graphene. Science 2008, 320, 1308. [CrossRef] [PubMed]

3. Kuzmenko, A.B.; van Heumen, E.; Carbone, F.; van der Marel, D. Universal optical conductance of graphite. Phys. Rev. Lett. 2008, 100, 117401. [CrossRef] [PubMed]

4. Pang, S.; Hernandez, Y.; Feng, X.; Müllen, K. Graphene as transparent electrode material for organic electronics. Adv. Mater. 2011, 23, 2779-2795. [CrossRef] [PubMed]

5. Li, Z.Q.; Henriksen, E.A.; Jiang, Z.; Hao, Z.; Martin, M.C.; Kim, P.; Stormer, H.L.; Basov, D.N. Dirac charge dynamics in graphene by infrared spectroscopy. Nat. Phys. 2008, 4, 532-535. [CrossRef]

6. Bernardi, M.; Palummo, M.; Grossman, J.C. Extraordinary sunlight absorption and one nanometer thick photovoltaics using two-dimensional monolayer materials. Nano Lett. 2013, 13, 3664-3670. [CrossRef] [PubMed]

7. Splendiani, A.; Sun, L.; Zhang, Y.; Li, T.; Kim, J.; Chim, C.-Y.; Galli, G.; Wang, F. Emerging photoluminescence in monolayer $\mathrm{MoS}_{2}$. Nano Lett. 2010, 10, 1271-1275. [CrossRef] [PubMed]

8. Li, J.; Majety, S.; Dahal, R.; Zhao, W.P.; Lin, J.Y.; Jiang, H.X. Dielectric strength, optical absorption, and deep ultraviolet detectors of hexagonal boron nitride epilayers. Appl. Phys. Lett. 2012, 101, 171112. [CrossRef]

9. Kataria, S.; Wagner, S.; Ruhkopf, J.; Gahoi, A.; Pandey, H.; Bornemann, R.; Vaziri, S.; Smith, A.D.; Ostling, M.; Lemme, M.C. Chemical vapor deposited graphene: From synthesis to applications. Phys. Status Solidi A 2014, 211, 2439-2449. [CrossRef]

10. Chhowalla, M.; Shin, H.S.; Eda, G.; Li, L.-J.; Loh, K.P.; Zhang, H. The chemistry of two-dimensional layered transition metal dichalcogenide nanosheets. Nat. Chem. 2013, 5, 263-275. [CrossRef] [PubMed]

11. Yamada, T.; Kim, J.; Ishihara, M.; Hasegawa, M. Low-temperature graphene synthesis using microwave plasma CVD. J. Phys. Appl. Phys. 2013, 46, 063001. [CrossRef]

12. Smith, A.; Vaziri, S.; Rodriguez, S.; Östling, M.; Lemme, M.C. Wafer scale graphene transfer for back end of the line device integration. In Proceedings of the 2014 15th International Conference on Ultimate Integration on Silicon (ULIS), Stockholm, Sweden, 7-9 April 2014.

13. Banszerus, L.; Schmitz, M.; Engels, S.; Dauber, J.; Oellers, M.; Haupt, F.; Watanabe, K.; Taniguchi, T.; Beschoten, B.; Stampfer, C. Ultrahigh-mobility graphene devices from chemical vapor deposition on reusable copper. Sci. Adv. 2015, 1, e1500222. [CrossRef] [PubMed]

14. Lupina, G.; Kitzmann, J.; Costina, I.; Lukosius, M.; Wenger, C.; Wolff, A.; Vaziri, S.; Östling, M.; Pasternak, I.; Krajewska, A.; et al. Residual metallic contamination of transferred chemical vapor deposited graphene. ACS Nano 2015. [CrossRef] [PubMed]

15. Wagner, S.; Weisenstein, C.; Smith, A.D.; Östling, M.; Kataria, S.; Lemme, M.C. Graphene transfer methods for the fabrication of membrane-based NEMS devices. Microelectron. Eng. 2016, 159, 108-113. [CrossRef]

16. Bae, S.; Kim, H.; Lee, Y.; Xu, X.; Park, J.-S.; Zheng, Y.; Balakrishnan, J.; Lei, T.; Kim, H.R.; Song, Y.I.; et al. Roll-to-roll production of 30-inch graphene films for transparent electrodes. Nat. Nanotechnol. 2010, 5, 574-578. [CrossRef] [PubMed]

17. Rahimi, S.; Tao, L.; Chowdhury, S.F.; Park, S.; Jouvray, A.; Buttress, S.; Rupesinghe, N.; Teo, K.; Akinwande, D. Toward $300 \mathrm{~mm}$ wafer-scalable high-performance polycrystalline chemical vapor deposited graphene transistors. ACS Nano 2014, 8, 10471-10479. [CrossRef] [PubMed]

18. Bae, S.; Kim, S.J.; Shin, D.; Ahn, J.-H.; Hong, B.H. Towards industrial applications of graphene electrodes. Phys. Scr. 2012, 2012, 014024. [CrossRef]

19. Bablich, A.; Watty, K.; Merfort, C.; Seibel, K.; Boehm, M. A novel high-dynamic A-Si:H multicolor pin-detector with ZnO:Al front and back contacts. In Proceedings of the 2010 MRS Fall Meeting: Symposium AA—Group IV Semiconductor Nanostructures and Applications, Boston, MA, USA, 29 November-3 December 2010; Volume 1305. 
20. Hamberg, I.; Granqvist, C.G. Evaporated Sn-doped $\operatorname{In}_{2} \mathrm{O}_{3}$ films: Basic optical properties and applications to energy-efficient windows. J. Appl. Phys. 1986, 60, R123-R160. [CrossRef]

21. Minami, T. Transparent conducting oxide semiconductors for transparent electrodes. Semicond. Sci. Technol. 2005, 20, S35-S44. [CrossRef]

22. Granqvist, C.G. Transparent conductors as solar energy materials: A panoramic review. Sol. Energy Mater. Sol. Cells 2007, 91, 1529-1598. [CrossRef]

23. Engadget. Samsung Showcases 4.5-Inch Flexible AMOLED, May Actually Mass Produce This One. Available online: http://www.engadget.com/2010/11/04/samsung-showcases-4-5-inch-flexible-amoled-mayactually-mass-pr/ (accessed on 1 October 2015).

24. Pocket-Lint. Plastic Logic Shows Off Colour e-Paper Display Smart Watch Concept: The Future of Wearable Tech? Available online: http://www.pocket-lint.com/news/120209-plastic-logiccolour-e-paper-smart-watch-concept (accessed on 1 October 2015).

25. Koppens, F.H.L.; Mueller, T.; Avouris, P.; Ferrari, A.C.; Vitiello, M.S.; Polini, M. Photodetectors based on graphene, other two-dimensional materials and hybrid systems. Nat. Nanotechnol. 2014, 9, 780-793. [CrossRef] [PubMed]

26. Wu, Z.; Chen, Z.; Du, X.; Logan, J.M.; Sippel, J.; Nikolou, M.; Kamaras, K.; Reynolds, J.R.; Tanner, D.B.; Hebard, A.F.; et al. Transparent, conductive carbon nanotube films. Science 2004, 305, 1273-1276. [CrossRef] [PubMed]

27. De, S.; Coleman, J.N. Are there fundamental limitations on the sheet resistance and transmittance of thin graphene films? ACS Nano 2010, 4, 2713-2720. [CrossRef] [PubMed]

28. Lee, J.-Y.; Connor, S.T.; Cui, Y.; Peumans, P. Solution-processed metal nanowire mesh transparent electrodes. Nano Lett. 2008, 8, 689-692. [CrossRef] [PubMed]

29. Bonaccorso, F.; Sun, Z.; Hasan, T.; Ferrari, A.C. Graphene photonics and optoelectronics. Nat. Photonics 2010, 4, 611-622. [CrossRef]

30. Sahu, D.R.; Lin, S.-Y.; Huang, J.-L. ZnO/Ag/ZnO multilayer films for the application of a very low resistance transparent electrode. Appl. Surf. Sci. 2006, 252, 7509-7514. [CrossRef]

31. De, S.; Higgins, T.M.; Lyons, P.E.; Doherty, E.M.; Nirmalraj, P.N.; Blau, W.J.; Boland, J.J.; Coleman, J.N. Silver nanowire networks as flexible, transparent, conducting films: Extremely high dc to optical conductivity ratios. ACS Nano 2009, 3, 1767-1774. [CrossRef] [PubMed]

32. Vivien, L.; Polzer, A.; Marris-Morini, D.; Osmond, J.; Hartmann, J.M.; Crozat, P.; Cassan, E.; Kopp, C.; Zimmermann, H.; Fédéli, J.M. Zero-bias $40 \mathrm{Gbit} / \mathrm{s}$ germanium waveguide photodetector on silicon. Opt. Express 2012, 20, 1096-1101. [CrossRef] [PubMed]

33. Wirths, S.; Geiger, R.; von den Driesch, N.; Mussler, G.; Stoica, T.; Mantl, S.; Ikonic, Z.; Luysberg, M.; Chiussi, S.; Hartmann, J.M. Lasing in direct-bandgap GeSn alloy grown on Si. Nat. Photonics 2015, 9, 88-92. [CrossRef]

34. Lemme, M.C.; Koppens, F.H.L.; Falk, A.L.; Rudner, M.S.; Park, H.; Levitov, L.S.; Marcus, C.M. Gate-activated photoresponse in a graphene $\mathrm{p}-\mathrm{n}$ junction. Nano Lett. 2011, 11, 4134-4137. [CrossRef] [PubMed]

35. Farmer, D.B.; Golizadeh-Mojarad, R.; Perebeinos, V.; Lin, Y.-M.; Tulevski, G.S.; Tsang, J.C.; Avouris, P. Chemical doping and electron-hole conduction asymmetry in graphene devices. Nano Lett. 2008, 9, 388-392. [CrossRef] [PubMed]

36. Sherpa, S.D.; Kunc, J.; Hu, Y.; Levitin, G.; de Heer, W.A.; Berger, C.; Hess, D.W. Local work function measurements of plasma-fluorinated epitaxial graphene. Appl. Phys. Lett. 2014, 104, 081607. [CrossRef]

37. Mueller, T.; Xia, F.; Avouris, P. Graphene photodetectors for high-speed optical communications. Nat. Photonics 2010, 4, 297-301. [CrossRef]

38. Rao, G.; Freitag, M.; Chiu, H.-Y.; Sundaram, R.S.; Avouris, P. Raman and photocurrent imaging of electrical stress-induced p-n junctions in graphene. ACS Nano 2011, 5, 5848-5854. [CrossRef] [PubMed]

39. Freitag, M.; Low, T.; Xia, F.; Avouris, P. Photoconductivity of biased graphene. Nat. Photonics 2013, 7, 53-59. [CrossRef]

40. Gabor, N.M.; Song, J.C.W.; Ma, Q.; Nair, N.L.; Taychatanapat, T.; Watanabe, K.; Taniguchi, T.; Levitov, L.S.; Jarillo-Herrero, P. Hot carrier-assisted intrinsic photoresponse in graphene. Science 2011, 334, 648-652. [CrossRef] [PubMed]

41. Song, J.C.W.; Rudner, M.S.; Marcus, C.M.; Levitov, L.S. Hot carrier transport and photocurrent response in graphene. Nano Lett. 2011, 11, 4688-4692. [CrossRef] [PubMed]

42. Kim, M.-H.; Yan, J.; Suess, R.J.; Murphy, T.E.; Fuhrer, M.S.; Drew, H.D. Photothermal response in dual-gated bilayer graphene. Phys. Rev. Lett. 2013, 110, 247402. [CrossRef] [PubMed] 
43. Tielrooij, K.J.; Song, J.C.W.; Jensen, S.A.; Centeno, A.; Pesquera, A.; Zurutuza Elorza, A.; Bonn, M.; Levitov, L.S.; Koppens, F.H.L. Photoexcitation cascade and multiple hot-carrier generation in graphene. Nat. Phys. 2013, 9, 248-252. [CrossRef]

44. Freitag, M.; Low, T.; Avouris, P. Increased responsivity of suspended graphene photodetectors. Nano Lett. 2013, 13, 1644-1648. [CrossRef] [PubMed]

45. Park, J.; Ahn, Y.H.; Ruiz-Vargas, C. Imaging of photocurrent generation and collection in single-layer graphene. Nano Lett. 2009, 9, 1742-1746. [CrossRef] [PubMed]

46. Lee, E.J.H.; Balasubramanian, K.; Weitz, R.T.; Burghard, M.; Kern, K. Contact and edge effects in graphene devices. Nat. Nanotechnol. 2008, 3, 486-490. [CrossRef] [PubMed]

47. Xia, F.; Mueller, T.; Golizadeh-Mojarad, R.; Freitag, M.; Lin, Y.; Tsang, J.; Perebeinos, V.; Avouris, P. Photocurrent imaging and efficient photon detection in a graphene transistor. Nano Lett. 2009, 9, 1039-1044. [CrossRef] [PubMed]

48. Mueller, T.; Xia, F.; Freitag, M.; Tsang, J.; Avouris, P. Role of contacts in graphene transistors: A scanning photocurrent study. Phys. Rev. B 2009, 79, 245430. [CrossRef]

49. Withers, F.; Bointon, T.H.; Craciun, M.F.; Russo, S. All-graphene photodetectors. ACS Nano 2013, 7, 5052-5057. [CrossRef] [PubMed]

50. Echtermeyer, T.J.; Nene, P.S.; Trushin, M.; Gorbachev, R.V.; Eiden, A.L.; Milana, S.; Sun, Z.; Schliemann, J.; Lidorikis, E.; Novoselov, K.S.; et al. Photothermoelectric and photoelectric contributions to light detection in metal-graphene-metal photodetectors. Nano Lett. 2014, 14, 3733-3742. [CrossRef] [PubMed]

51. Pospischil, A.; Humer, M.; Furchi, M.M.; Bachmann, D.; Guider, R.; Fromherz, T.; Mueller, T. CMOS-compatible graphene photodetector covering all optical communication bands. Nat. Photonics 2013, 7, 892-896. [CrossRef]

52. Naiini, M.M.; Vaziri, S.; Smith, A.D.; Lemme, M.C.; Ostling, M. Embedded graphene photodetectors for silicon photonics. In Proceedings of the 2014 72nd Annual Device Research Conference (DRC), Santa Barbara, CA, USA, 22-25 June 2014; pp. 43-44.

53. Liu, M.; Yin, X.; Ulin-Avila, E.; Geng, B.; Zentgraf, T.; Ju, L.; Wang, F.; Zhang, X. A graphene-based broadband optical modulator. Nature 2011, 474, 64-67. [CrossRef] [PubMed]

54. Schall, D.; Neumaier, D.; Mohsin, M.; Chmielak, B.; Bolten, J.; Porschatis, C.; Prinzen, A.; Matheisen, C.; Kuebart, W.; Junginger, B.; et al. 50 GBit/s photodetectors based on wafer-scale graphene for integrated silicon photonic communication systems. ACS Photonics 2014, 1, 781-784. [CrossRef]

55. Chen, L.; Lipson, M. Ultra-low capacitance and high speed germanium photodetectors on silicon. Opt. Express 2009, 17, 7901-7906. [CrossRef] [PubMed]

56. Chen, C.-C.; Aykol, M.; Chang, C.-C.; Levi, A.F..; Cronin, S.B. Graphene-silicon schottky diodes. Nano Lett. 2011, 11, 1863-1867. [CrossRef] [PubMed]

57. Riazimehr, S.; Schneider, D.; Yim, C.; Kataria, S.; Passi, V.; Bablich, A.; Duesberg, G.S.; Lemme, M.C. Spectral sensitivity of a graphene/silicon pn-junction photodetector. In Proceedings of the 2015 Joint International EUROSOI Workshop and International Conference on Ultimate Integration on Silicon (EUROSOI-ULIS), Bologna, Italy, 26-28 January 2015.

58. Smith, A.D.; Elgammal, K.; Niklaus, F.; Delin, A.; Fischer, A.C.; Vaziri, S.; Forsberg, F.; Råsander, M.; Hugosson, H.; Bergqvist, L.; et al. Resistive graphene humidity sensors with rapid and direct electrical readout. Nanoscale 2015, 7, 19099-19109. [CrossRef] [PubMed]

59. Cusati, T.; Fiori, G.; Gahoi, A.; Fortunelli, A.; Lemme, M.C.; Iannaccone, G. Electrical properties of graphene-metal contacts.: A theoretical and experimental study. In Proceedings of The IEEE International Electron Device Meeting IEDM, Washington, DC, USA, 7-9 December 2015.

60. An, X.; Liu, F.; Jung, Y.J.; Kar, S. Tunable graphene-silicon heterojunctions for ultrasensitive photodetection. Nano Lett. 2013, 13, 909-916. [CrossRef] [PubMed]

61. Kim, H.-Y.; Lee, K.; McEvoy, N.; Yim, C.; Duesberg, G.S. Chemically modulated graphene diodes. Nano Lett. 2013, 13, 2182-2188. [CrossRef] [PubMed]

62. Winzer, T.; Knorr, A.; Malic, E. Carrier multiplication in graphene. Nano Lett. 2010, 10, 4839-4843. [CrossRef] [PubMed]

63. Plötzing, T.; Winzer, T.; Malic, E.; Neumaier, D.; Knorr, A.; Kurz, H. Experimental verification of carrier multiplication in graphene. Nano Lett. 2014, 14, 5371-5375. [CrossRef] [PubMed] 
64. Zhang, J.; Zhu, Z.; Liu, W.; Yuan, X.; Qin, S. Graphene Plasmonics for Light Trapping and Absorption Engineering in optoelectronic devices; Frontiers in Optics: San Diego, CA, USA, 2015.

65. Peters, E.C.; Lee, E.J.H.; Burghard, M.; Kern, K. Gate dependent photocurrents at a graphene p-n junction. Appl. Phys. Lett. 2010, 97, 193102. [CrossRef]

66. Gilbertson, A.M.; Francescato, Y.; Roschuk, T.; Shautsova, V.; Chen, Y.; Sidiropoulos, T.P.H.; Hong, M.; Giannini, V.; Maier, S.A.; Cohen, L.F.; et al. Plasmon-induced optical anisotropy in hybrid graphene-metal nanoparticle systems. Nano Lett. 2015, 15, 3458-3464. [CrossRef] [PubMed]

67. Engel, M.; Steiner, M.; Lombardo, A.; Ferrari, A.C.; v Löhneysen, H.; Avouris, P.; Krupke, R. Light-matter interaction in a microcavity-controlled graphene transistor. Nat. Commun. 2012, 3, 906. [CrossRef] [PubMed]

68. Furchi, M.; Urich, A.; Pospischil, A.; Lilley, G.; Unterrainer, K.; Detz, H.; Klang, P.; Andrews, A.M.; Schrenk, W.; Strasser, G.; et al. Microcavity-integrated graphene photodetector. Nano Lett. 2012, 12, 2773-2777. [CrossRef] [PubMed]

69. Liu, Y.; Cheng, R.; Liao, L.; Zhou, H.; Bai, J.; Liu, G.; Liu, L.; Huang, Y.; Duan, X. Plasmon resonance enhanced multicolour photodetection by graphene. Nat. Commun. 2011, 2, 579. [CrossRef] [PubMed]

70. Huisman, E.H.; Shulga, A.G.; Zomer, P.J.; Tombros, N.; Bartesaghi, D.; Bisri, S.Z.; Loi, M.A.; Koster, L.J.A.; van Wees, B.J. High gain hybrid graphene-organic semiconductor phototransistors. ACS Appl. Mater. Interfaces 2015, 7, 11083-11088. [CrossRef] [PubMed]

71. Echtermeyer, T.J.; Britnell, L.; Jasnos, P.K.; Lombardo, A.; Gorbachev, R.V.; Grigorenko, A.N.; Geim, A.K.; Ferrari, A.C.; Novoselov, K.S. Strong plasmonic enhancement of photovoltage in graphene. Nat. Commun. 2011, 2, 458. [CrossRef] [PubMed]

72. Dang, V.Q.; Trung, T.Q.; Kim, D.-I.; Duy, L.T.; Hwang, B.-U.; Lee, D.-W.; Kim, B.-Y.; Toan, L.D.; Lee, N.-E. Ultrahigh responsivity in graphene-ZnO nanorod hybrid UV photodetector. Small 2015, 11, 3054-3065. [CrossRef] [PubMed]

73. Konstantatos, G.; Sargent, E.H. Solution-processed quantum dot photodetectors. IEEE Proc. 2009, 97, 1666-1683. [CrossRef]

74. Konstantatos, G.; Badioli, M.; Gaudreau, L.; Osmond, J.; Bernechea, M.; de Arquer, F.P.G.; Gatti, F.; Koppens, F.H.L. Hybrid graphene-quantum dot phototransistors with ultrahigh gain. Nat. Nanotechnol. 2012, 7, 363-368. [CrossRef] [PubMed]

75. Zhang, D.; Gan, L.; Cao, Y.; Wang, Q.; Qi, L.; Guo, X. Understanding charge transfer at PbS-decorated graphene surfaces toward a tunable photosensor. Adv. Mater. 2012, 24, 2715-2720. [CrossRef] [PubMed]

76. Sun, Z.; Liu, Z.; Li, J.; Tai, G.; Lau, S.-P.; Yan, F. Infrared photodetectors based on CVD-grown graphene and $\mathrm{PbS}$ quantum dots with ultrahigh responsivity. Adv. Mater. 2012, 24, 5878-5883. [CrossRef] [PubMed]

77. Turyanska, L.; Makarovsky, O.; Svatek, S.A.; Beton, P.H.; Mellor, C.J.; Patanè, A.; Eaves, L.N.; Thomas, R.; Fay, M.W.; Marsden, A.J.; et al. Ligand-induced control of photoconductive gain and doping in a hybrid graphene-quantum dot transistor. Adv. Electron. Mater. 2015. [CrossRef]

78. Zhang, Y.; Song, X.; Wang, R.; Cao, M.; Wang, H.; Che, Y.; Ding, X.; Yao, J. Comparison of photoresponse of transistors based on graphene-quantum dot hybrids with layered and bulk heterojunctions. Nanotechnology 2015, 26, 335201. [CrossRef] [PubMed]

79. Lopez-Sanchez, O.; Lembke, D.; Kayci, M.; Radenovic, A.; Kis, A. Ultrasensitive photodetectors based on monolayer $\mathrm{MoS}_{2}$. Nat. Nanotechnol. 2013, 8, 497-501. [CrossRef] [PubMed]

80. Zhang, W.; Huang, J.-K.; Chen, C.-H.; Chang, Y.-H.; Cheng, Y.-J.; Li, L.-J. High-gain phototransistors based on a CVD MoS 2 monolayer. Adv. Mater. 2013, 25, 3456-3461. [CrossRef] [PubMed]

81. Krainak, M.A.; Sun, X.; Yang, G.; Lu, W. Comparison of linear-mode avalanche photodiode lidar receivers for use at one-micron wavelength. In Proceedings of the SPIE 7681: Advanced Photon Counting Techniques IV, Orlando, FL, USA; 2010; Volume 7681, pp. 76810Y-76810Y-13.

82. Kufer, D.; Konstantatos, G. Highly sensitive, encapsulated $\mathrm{MoS}_{2}$ photodetector with gate controllable gain and speed. Nano Lett. 2015, 15, 7307-7313. [CrossRef] [PubMed]

83. Pospischil, A.; Furchi, M.M.; Mueller, T. Solar-energy conversion and light emission in an atomic monolayer p-n diode. Nat. Nano. 2014, 9, 257-261. [CrossRef] [PubMed]

84. Lopez-Sanchez, O.; Alarcon Llado, E.; Koman, V.; Fontcuberta i Morral, A.; Radenovic, A.; Kis, A. Light generation and harvesting in a van der Waals Heterostructure. ACS Nano 2014, 8, 3042-3048. [CrossRef] [PubMed] 
85. Yim, C.; O’Brien, M.; McEvoy, N.; Riazimehr, S.; Schafer-Eberwein, H.; Bablich, A.; Pawar, R.; Iannaccone, G.; Downing, C.; Fiori, G.; et al. Heterojunction hybrid devices from vapor phase grown $\mathrm{MoS}_{2}$. Sci. Rep. 2014, 4, 5458. [CrossRef] [PubMed]

86. Furchi, M.M.; Pospischil, A.; Libisch, F.; Burgdörfer, J.; Mueller, T. Photovoltaic effect in an electrically tunable van der Waals Heterojunction-Nano letters. Nano Lett. 2014, 14, 4785-4791. [CrossRef] [PubMed]

87. Lee, C.-H.; Lee, G.-H.; van der Zande, A.M.; Chen, W.; Li, Y.; Han, M.; Cui, X.; Arefe, G.; Nuckolls, C.; Heinz, T.F.; et al. Atomically thin $\mathrm{p}-\mathrm{n}$ junctions with van der Waals heterointerfaces. Nat. Nanotechnol. 2014, 9, 676-681. [CrossRef] [PubMed]

88. Cheng, R.; Li, D.; Zhou, H.; Wang, C.; Yin, A.; Jiang, S.; Liu, Y.; Chen, Y.; Huang, Y.; Duan, X. Electroluminescence and photocurrent generation from atomically sharp $\mathrm{WSe}_{2} / \mathrm{MoS}_{2}$ heterojunction $\mathrm{p}-\mathrm{n}$ diodes. Nano Lett. 2014, 14, 5590-5597. [CrossRef] [PubMed]

89. Wang, Z.; Xu, K.; Li, Y.; Zhan, X.; Safdar, M.; Wang, Q.; Wang, F.; He, J. Role of Ga vacancy on a multilayer GaTe phototransistor. ACS Nano 2014, 8, 4859-4865. [CrossRef] [PubMed]

90. Britnell, L.; Ribeiro, R.M.; Eckmann, A.; Jalil, R.; Belle, B.D.; Mishchenko, A.; Kim, Y.-J.; Gorbachev, R.V.; Georgiou, T.; Morozov, S.V.; et al. Strong light-matter interactions in Heterostructures of atomically thin films. Science 2013, 340, 1311-1314. [CrossRef] [PubMed]

91. Shi, Y.; Li, H.; Li, L.-J. Recent advances in controlled synthesis of two-dimensional transition metaldichalcogenides via vapour deposition techniques. Chem. Soc. Rev. 2015, 44, 2744-2756. [CrossRef] [PubMed]

92. Han, G.H.; Rodríguez-Manzo, J.A.; Lee, C.-W.; Kybert, N.J.; Lerner, M.B.; Qi, Z.J.; Dattoli, E.N.; Rappe, A.M.; Drndic, M.; Johnson, A.T.C. Continuous growth of hexagonal graphene and boron nitride in-plane heterostructures by atmospheric pressure chemical vapor deposition. ACS Nano 2013, 7, 10129-10138. [CrossRef] [PubMed]

93. Gao, T.; Song, X.; Du, H.; Nie, Y.; Chen, Y.; Ji, Q.; Sun, J.; Yang, Y.; Zhang, Y.; Liu, Z. Temperature-triggered chemical switching growth of in-plane and vertically stacked graphene-boron nitride heterostructures. Nat. Commun. 2015, 6, 6835. [CrossRef] [PubMed]

94. Shi, Y.; Zhou, W.; Lu, A.-Y.; Fang, W.; Lee, Y.-H.; Hsu, A.L.; Kim, S.M.; Kim, K.K.; Yang, H.Y.; Li, L.-J.; et al. van der Waals Epitaxy of $\mathrm{MoS}_{2}$ Layers Using Graphene as Growth Templates. Nano Lett. 2012, 12, 2784-2791. [CrossRef] [PubMed]

95. Lin, Y.-C.; Lu, N.; Perea-Lopez, N.; Li, J.; Lin, Z.; Peng, X.; Lee, C.H.; Sun, C.; Calderin, L.; Browning, P.N.; et al. Direct synthesis of van der Waals solids. ACS Nano 2014, 8, 3715-3723. [CrossRef]

96. Gong, Y.; Lin, J.; Wang, X.; Shi, G.; Lei, S.; Lin, Z.; Zou, X.; Ye, G.; Vajtai, R.; Yakobson, B.I.; et al. Vertical and in-plane heterostructures from $\mathrm{WS}_{2} / \mathrm{MoS}_{2}$ monolayers. Nat. Mater. 2014, 13, 1135-1142. [CrossRef] [PubMed]

97. Li, M.-Y.; Shi, Y.; Cheng, C.-C.; Lu, L.-S.; Lin, Y.-C.; Tang, H.-L.; Tsai, M.-L.; Chu, C.-W.; Wei, K.-H.; He, J.-H.; et al. Epitaxial growth of a monolayer $\mathrm{WSe}_{2}-\mathrm{MoS}_{2}$ lateral $\mathrm{p}-\mathrm{n}$ junction with an atomically sharp interface. Science 2015, 349, 524-528. [CrossRef] [PubMed]

98. Wang, X.; Cheng, Z.; Xu, K.; Tsang, H.K.; Xu, J.-B. High-responsivity graphene/silicon-heterostructure waveguide photodetectors. Nat. Photonics 2013, 7, 888-891. [CrossRef]

99. Xu, K.; Xu, C.; Xie, Y.; Deng, J.; Zhu, Y.; Guo, W.; Xun, M.; Teo, K.B.K.; Chen, H.; Sun, J. Graphene GaN-based schottky ultraviolet detectors. IEEE Trans. Electron Devices 2015, 62, 2802-2808. [CrossRef]

100. Spirito, D.; Coquillat, D.; Bonis, S.L.D.; Lombardo, A.; Bruna, M.; Ferrari, A.C.; Pellegrini, V.; Tredicucci, A.; Knap, W.; Vitiello, M.S. High performance bilayer-graphene terahertz detectors. Appl. Phys. Lett. 2014, 104, 061111. [CrossRef]

101. Liu, Z.; Parvez, K.; Li, R.; Dong, R.; Feng, X.; Müllen, K. Transparent conductive electrodes from Graphene/PEDOT:PSS hybrid inks for ultrathin organic photodetectors. Adv. Mater. 2015, 27, 669-675. [CrossRef] [PubMed]

102. Zhang, W.; Chu, C.-P.; Huang, J.-K.; Chen, C.-H.; Tsai, M.-L.; Chang, Y.-H.; Liang, C.-T.; Chen, Y.-Z.; Chueh, Y.-L.; He, J.-H.; et al. Ultrahigh-gain photodetectors based on atomically thin Graphene- $\mathrm{MoS}_{2}$ heterostructures. Sci. Rep. 2014, 4. [CrossRef] [PubMed]

(C) 2016 by the authors; licensee MDPI, Basel, Switzerland. This article is an open access article distributed under the terms and conditions of the Creative Commons by Attribution (CC-BY) license (http:/ / creativecommons.org/licenses/by/4.0/). 